\title{
AN OBSERVATION FOR SIMPLE EXPANSIONS
}

\author{
DAVIO A. ROSE and DRAGan A. Janković
}

Department of Mathematics, last Central University, Ada, OK T4820

(Received March 26, 1991)

1980 MATIEMATICS SUBJECT CLASSIFICATION: 54A10, 54B05

If $(X, \tau)$ is a topological space and $\Lambda \subseteq X$, the simple expansion of $\tau$ by $A$ is the topology $\tau(A)=$ $\{U \cup(V \cap A) \mid U, V \in \tau\}$. Let us say that a topological property is weakly finitely additive if whenever closed subspaces A and B have the property then so does AUB. Recall that a property is weakly (open) hereditary if closed (open) subspaces inherit it. It is well known that certain weakly hereditary, weakly finitely additive properties such as normality, paracompactness, and the Lindelöf property, lift from $(\mathrm{X}, \tau)$ to $(\mathrm{X}, \tau(\mathrm{A}))$ if and only if $(\mathrm{X}-\mathrm{A}, \tau \mid(\mathrm{X}-\mathrm{A}))$ has the property, when $(\mathrm{X}, \tau)$, and $(\mathrm{X}, \tau(\mathrm{A}))$ are regular [6]. As in [2], a property is contagious if whenever a dense subspace has the property then so docs the entire space. Without any need for regularity or any separation we have the following simple observation.

Theorem. If $P$ is open hereditary, contagious, and weakly finitely additive, then $(X, \tau(A))$ has $P$ if and only if both $(X, \tau)$ and $(A, \tau \mid A)$ have $P$ (where $\tau \mid A$ is the subspace topology).

The proof is a consequence of the easy facts that $\mathrm{A} \in \tau(\mathrm{A}), \mathrm{Cl}_{\tau} \mathrm{A}=\mathrm{Cl}_{\tau(\mathrm{A})} \mathrm{A}$, and $\tau(\mathrm{A})|\mathrm{B}=\tau| \mathrm{B}$ for $\mathrm{B}$ $=\mathrm{A}$ or X-A. Among others, properties satisfying the hypotheses of the theorem include Baireness [4], resolvability, and separability. One consequence is that $(R, \tau(I))$ is a Baire space and hence second category if $(R, r)$ is the usual space of real numbers and $I$ is the subset of irrationals. This fills a classification hole in [7].

\section{REFERENCES}

1. C. J. R. Borges, On extensions of topologies, Candian J. Math., 19 (1967) 474-487.

2. J. Chew, Contagious properties, Mathematics Magazine, 47 (1974) 84-87.

3. J. Dugundji, Topology, Allyn and Bacon, Inc., Boston, MA, 1966.

4. R. Haworth and R. McCoy, Baire spaces, Dissertationes Mathematicae 141, Polish Scientific Publishers, Warsaw, 1977.

5. N. Levine, Simple extensions of topologies, American Mathematzcal Monthly, 71 (1964) 22-25.

6. D. F. Reynolds, Simple extensions of topologies, Topology: Proceedings of the Memphis State University Conference, Marcel Dekker, Inc., New York, NY, 1976, pages 239-242.

7. L. A. Stcen and J. A. Seebach, Jr., Counterexamples in Topology, llold, Rinehart and Winston, Inc., New York, NY, 1970. 


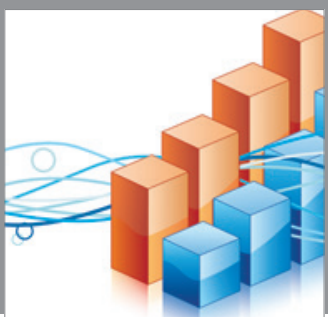

Advances in

Operations Research

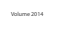

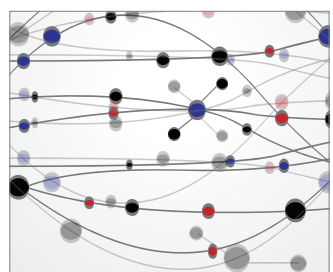

\section{The Scientific} World Journal
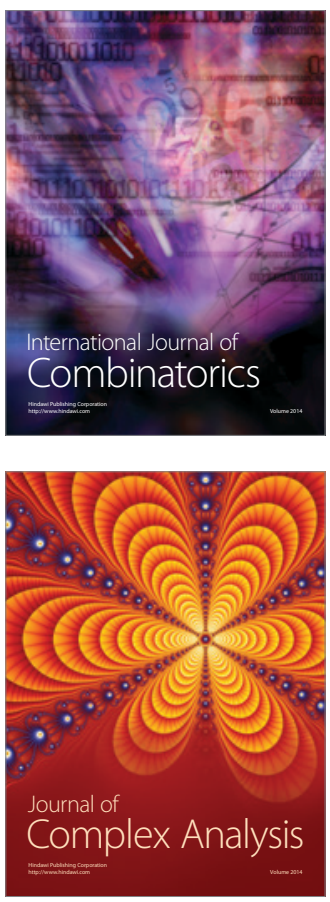

International Journal of

Mathematics and

Mathematical

Sciences
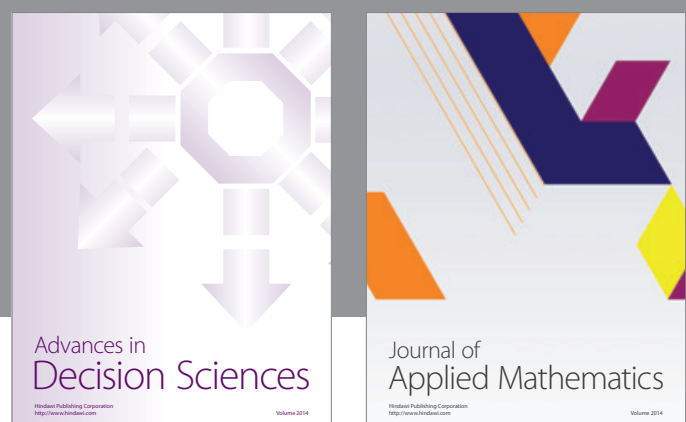

Journal of

Applied Mathematics
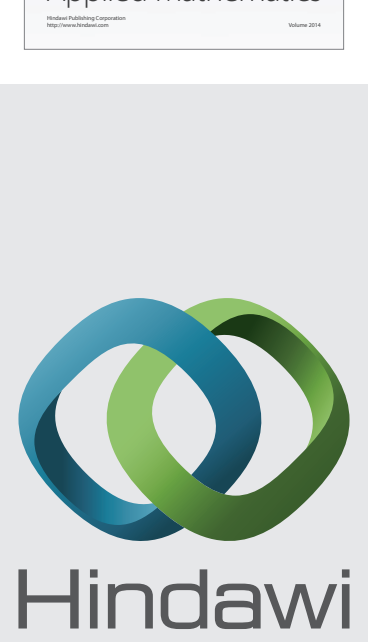

Submit your manuscripts at http://www.hindawi.com
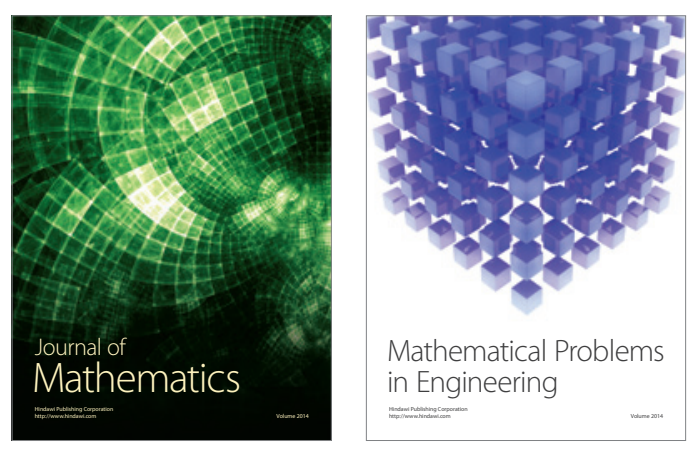

Mathematical Problems in Engineering
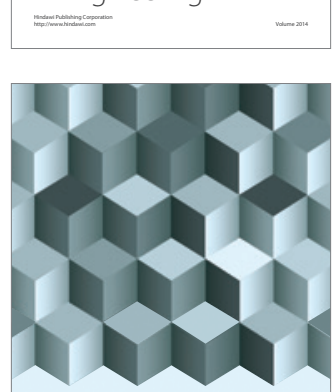

Journal of

Function Spaces
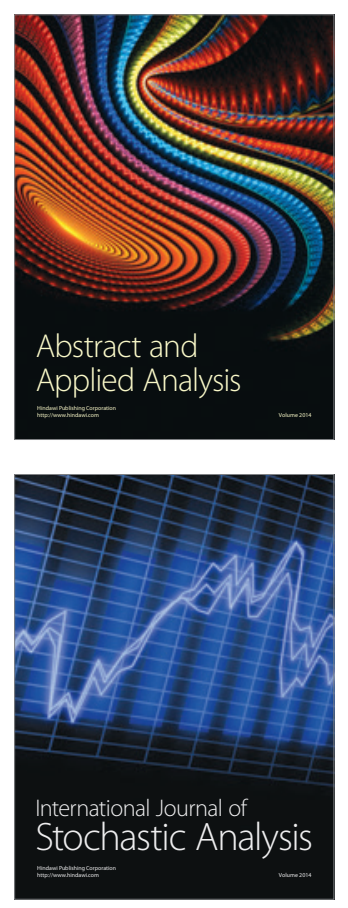

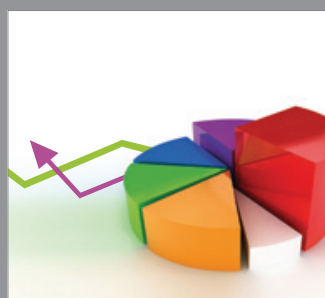

ournal of

Probability and Statistics

Promensencen
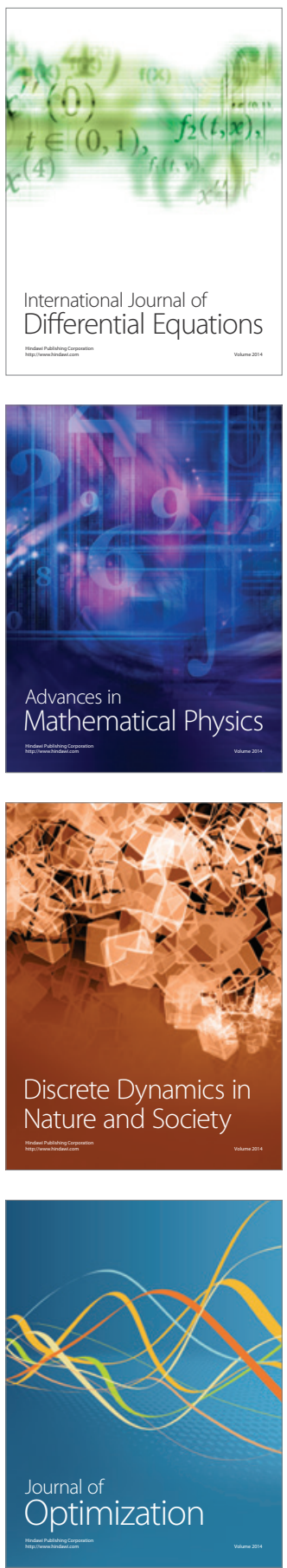